\title{
Determining Stroke Onset Time Using Quantitative MRI: High Accuracy, Sensitivity and Specificity Obtained from Magnetic Resonance Relaxation Times
}

\author{
Bryony L. McGarry ${ }^{a}$ Harriet J. Rogers ${ }^{b}$ Michael J. Knight ${ }^{a}$ \\ Kimmo T. Jokivarsic Olli H.J. Gröhn ${ }^{c}$ Risto A. Kauppinen ${ }^{a}$ \\ a School of Experimental Psychology, University of Bristol, Bristol, and b Imaging and \\ Biophysics, Institute of Child Health, University College London, London, UK; \\ 'Department of Neurobiology, University of Eastern Finland, Kuopio, Finland
}

\section{Key Words}

Quantitative MRI · Ischaemia · Wake-up stroke

\section{Abstract}

Many ischaemic stroke patients are ineligible for thrombolytic therapy due to unknown onset time. Quantitative MRI (qMRI) is a potential surrogate for stroke timing. Rats were subjected to permanent middle cerebral artery occlusion and qMRI parameters including hemispheric differences in apparent diffusion coefficient, $T_{2}$-weighted signal intensities, $T_{1}$ and $T_{2}$ relaxation times $\left(\mathrm{qT}_{1}, \mathrm{qT}_{2}\right)$ and $f_{1}, f_{2}$ and $V_{\text {overlap }}$ were measured at hourly intervals at 4.7 or $9.4 \mathrm{~T}$. Accuracy and sensitivity for identifying strokes scanned within and beyond $3 \mathrm{~h}$ of onset was determined. Accuracy for $V_{\text {overlap }} f_{2}$ and $\mathrm{qT}_{2}(>90 \%)$ was significantly higher than other parameters. At a specificity of 1 , sensitivity was highest for $V_{\text {overlap }}(0.90)$ and $f_{2}(0.80)$, indicating promise of these qMRI indices in the clinical assessment of stroke onset time.

\section{Introduction}

Ischaemic stroke patients are ineligible for thrombolytic treatment if time of symptom onset is unknown. Common reasons include lack of witness, being unaware of symptoms or wake-up stroke. MRI is sensitive to hydrodynamic changes in brain parenchyma caused by 
ischaemia [1]. A growing body of evidence suggests quantitative data from these changes could be informative of tissue status, aiding decision-making for clinical treatment $[1,2]$. Low sensitivity and ambiguity associated with relying on visual assessment of MR images prompted investigation into the potential utility of quantitative MRI (qMRI) for clinical needs [3].

Hemispheric differences in the apparent diffusion coefficient (ADC) [4], signal intensities of $\mathrm{T}_{2}$-weighted $\left(\mathrm{T}_{2}-\mathrm{w}\right)$ images (with and without FLAIR) [4-6] and quantitative $\mathrm{T}_{1}\left(\mathrm{qT}_{1}\right)$ [7] and $\mathrm{T}_{2}\left(\mathrm{qT}_{2}\right)$ relaxation times [5,7] correlate with time from stroke onset. This relationship is attributed to changes in tissue-water dynamics due to cytotoxic and/or vasogenic oedema [1] and enabled onset time to be determined with varying levels of accuracy [3-8]. In rat focal ischaemia, the spatial distribution and volume of abnormal $\mathrm{qT}_{1}$ or $\mathrm{qT}_{2}$ tissue is initially smaller than total ischaemia volume (delineated by decreased ADC) but increases with ischaemia duration $[5,7]$. We therefore proposed qMRI surrogates for stroke timing including $f_{1}$, $f_{2}$ and $V_{\text {overlap}}$, where $f_{1}$ and $f_{2}$ are the volume of tissue with elevated $\mathrm{qT}_{1}$ or $\mathrm{qT}_{2}$ as a percentage of total ischaemia volume, respectively, and $V_{\text {overlap }}$ is the volume with both elevated $\mathrm{qT}_{1}$ and $\mathrm{qT}_{2}$ normalised by the whole brain volume [7].

From a clinical perspective, a surrogate with high specificity is essential to minimise potential adverse events of thrombolysis. High sensitivity is also important to stratify as many patients as possible for thrombolysis. Accuracy of the above qMRI surrogates for stroke assessment has been reported in preclinical and clinical settings [3-8]. The objective of this study was to compare the accuracy and sensitivity of $\mathrm{ADC}, \mathrm{T}_{2}-\mathrm{w}, \mathrm{qT}_{1}, \mathrm{qT}_{2}, f_{1}, f_{2}$ and $V_{\text {overlap }}$ in a defined rat model of ischaemic stroke.

\section{Methods}

qMRI data from our previous studies [5,7] were used. Although $\mathrm{qT}_{1}$ and $\mathrm{qT}_{2}$ are dependent on magnetic field strength, combining data from $4.7 \mathrm{~T}$ and $9.4 \mathrm{~T}$, was not considered problematic as the net magnitude of $\mathrm{qT}_{1}$ and $\mathrm{qT}_{2}$ change due to ischaemia is independent of field strength during the initial hours of stroke [7].

\section{Animal Model}

Animal procedures were conducted according to European Community Council Directives 86/609/EEC guidelines and approved by the Animal Care and Use Committee of the University of Eastern Finland. Rats were anaesthetised with isoflurane (1.5-2\%). Twelve male Wistar rats (300-400 g) underwent permanent middle cerebral artery occlusion (MCAo) to induce focal ischaemia (see online supplementary information, available at www. karger.com/doi/10.1159/000448814). During MRI, breathing rate and rectal temperature were monitored and core temperature maintained at $37^{\circ} \mathrm{C}$ with a water heating pad. After MRI, rats were sacrificed [5, 7].

\section{MRI}

Rats were scanned at $4.7 \mathrm{~T}(\mathrm{n}=7)$ or $9.4 \mathrm{~T}(\mathrm{n}=5)$ for 7 or 5 h post MCAo, respectively [5, 7]. Every hour, axial slices of FLASH $\mathrm{T}_{1}$ (9.4 $\mathrm{T}$ only), trace of diffusion tensor $\left(\mathrm{D}_{\mathrm{av}}\right.$ ) for ADC quantification and multi-echo $\mathrm{T}_{2}$ were acquired. $4.7 \mathrm{~T}$ data was single-slice and 9.4 $\mathrm{T}$ was multi-slice $(n=12)$. The online supplementary information provides details of MRI data acquisition parameters.

\section{Image Postprocessing and Data Analyses}

Image postprocessing and data analysis, including quantification of $A D C, \mathrm{~T}_{2}-\mathrm{w}, \mathrm{qT}_{1}, \mathrm{qT}_{2}$, $f_{1}, f_{2}$ and $V_{\text {overlap, }}$ was carried out on all MR data acquired from each rat at every hour post 


\section{Cerebirovascular \\ Diseases}

Table 1. Sensitivity of qMRI parameters for discriminating between scans performed within and beyond $3 \mathrm{~h}$ of stroke onset, when specificity is set at 1

\begin{tabular}{l}
\hline Cerebrovasc Dis Extra 2016;6:60-65 \\
\hline DOI: 10.1159/000448814 \\
$\begin{array}{l}\text { (c) 2016 The Author(s). Published by S. Karger AG, Basel } \\
\text { www.karger.com/cee }\end{array}$
\end{tabular}

McGarry et al.: Determining Stroke Onset Time Using Quantitative MRI: High Accuracy, Sensitivity and Specificity Obtained from Magnetic Resonance Relaxation Times

\begin{tabular}{lcll}
\hline Parameter & Threshold & $\begin{array}{l}\text { Specificity } \\
(95 \% \mathrm{CI})\end{array}$ & $\begin{array}{l}\text { Sensitivity } \\
(95 \% \mathrm{CI})\end{array}$ \\
\hline$V_{\text {overlap }}$ & $1.83 \%$ & $1(0.65-1)$ & $0.90(0.57-1.00)$ \\
$f_{2}$ & $69.71 \%$ & $1(0.65-1)$ & $0.80(0.48-0.95)$ \\
$f_{1}$ & $84.09 \%$ & $1(0.65-1)$ & $0.50(0.24-0.76)$ \\
$\mathrm{qT}_{2}$ & 0.99 & $1(0.85-1)$ & $0.39(0.24-0.56)$ \\
$\mathrm{T}_{2}-\mathrm{W}$ & 1.00 & $1(0.85-1)$ & $0.29(0.16-0.47)$ \\
$\mathrm{qT}_{1}$ & 0.99 & $1(0.65-1)$ & $0.10(0.00-0.43)$ \\
$\mathrm{ADC}$ & 0.79 & $1(0.77-1)$ & $0.00(0.00-0.12)$ \\
\hline
\end{tabular}

$\mathrm{CI}=$ Confidence interval. Thresholds for $f_{1}, f_{2}$ and $V_{\text {overlap }}$ are percentages, where $f_{1}$ and $f_{2}$ are the volume of $\mathrm{qT}_{1}$ or $\mathrm{qT}_{2}$ elevation within the ADC-defined ischaemic lesion as a percentage of the size of ischaemic volume, and $V_{\text {overlap }}$ is the percent of voxels with both $\mathrm{qT}_{1}$ and $\mathrm{qT}_{2}$ elevation within the ischaemic volume relative to the whole-brain size. $\mathrm{ADC}, \mathrm{qT}_{1}, \mathrm{qT}_{2}$ and $\mathrm{T}_{2}-\mathrm{w}$ are ischaemic/nonischaemic ratios.

MCAo. Matlab (MathWorks, Natick, Mass., USA) scripts written in-house or MRI data software 'Mango' (Research Imaging Institute, UT Health Science Centre at San Antonio, Tex., USA) were used. $\mathrm{qT}_{1}$ and $\mathrm{qT}_{2}$ maps were computed using a monoexponential approximation. Images for quantification of signal intensities were the sum of weighted images acquired at each echo time.

Ischaemic regions were identified as hypointense areas on $\mathrm{D}_{\mathrm{av}}$ images, all within the striatum, which is $100 \%$ grey matter [7]. Regions of interest (ROIs; $3 \mathrm{~mm}$ diameter) were placed in the ischaemic and homologous regions. ROIs were loaded onto corresponding weighted and relaxometry images. For $9.4 \mathrm{~T}$ data, a representative central slice from the comparable brain region to the $4.7 \mathrm{~T}$ data was chosen for analyses. Relative differences in $\mathrm{ADC}, \mathrm{T}_{2}-\mathrm{w}, \mathrm{qT}_{1}$ and $\mathrm{qT}_{2}$ were calculated by dividing the average value of the ischaemic ROI by the average nonischaemic ROI. Use of nonischaemic values was to eliminate intersubject variation. $f_{1}, f_{2}$ and $V_{\text {overlap }}$ values from our previous study [7] were used including all slices of the 9.4 $\mathrm{T}$ dataset (methods described in the online suppl. information). Signal-to-noise ratio (SNR), the key image quality characteristic, was computed for maps and summed weighted images using the dual acquisition approach (see online suppl. information).

\section{Statistical Analysis}

Areas under receiver operating characteristic (ROC) curves (AUCs) were calculated for each qMRI parameter for identification of scans acquired $\leq 3 \mathrm{~h}$ post MCAo. $\leq 3 \mathrm{~h}$ was chosen for comparison as both data sets contained this time point. Nonparametric pairwise comparisons of AUCs were performed (see online suppl. information) and sensitivity levels at a specificity of 1 determined.

\section{Results}

SNR was higher for weighted images but comparable across field strengths. SNR at $4.7 \mathrm{~T}$ was $31.4(\mathrm{SD}=7.1)$ for $\mathrm{qT}_{2}$, and $90.5(\mathrm{SD}=19.2)$ for $\mathrm{T}_{2}$-w. At 9.4 $\mathrm{T}$, SNR was $19.1(\mathrm{SD}=3.9)$ for $\mathrm{qT}_{2}$, and $59.2(\mathrm{SD}=23.0)$ for $\mathrm{T}_{2}$-w. Figure 1 shows ROC curves and AUCs. $V_{\text {overlap}}, f_{2}$ and $\mathrm{qT}_{2}$ had comparable accuracy $(\mathrm{p}>0.05)$ and were more accurate than $\mathrm{ADC}, \mathrm{T}_{2}-\mathrm{w}, \mathrm{qT}_{1}$ and $f_{1}$ $(\mathrm{p}<0.05)$. Table 1 shows that at a specificity of $1, V_{\text {overlap }}$ and $f_{2}$ were most sensitive. Thresholds 


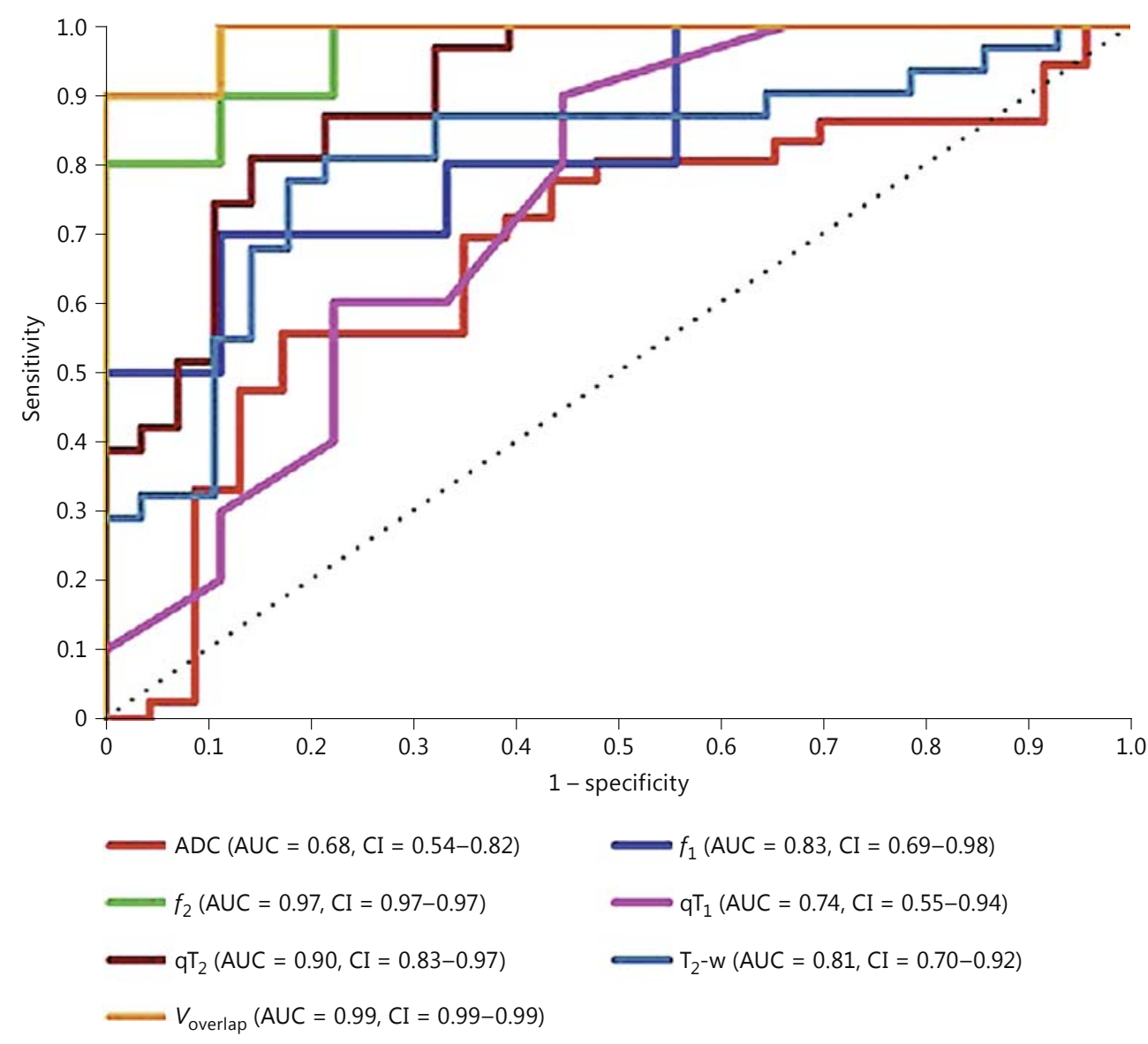

Fig. 1. ROC curves and AUC of qMRI parameters for discriminating between scans performed within and beyond $3 \mathrm{~h}$ of stroke onset. $\mathrm{CI}=95 \%$ confidence interval.

for identifying strokes $\leq 3 \mathrm{~h}$ at these specificity and sensitivity levels are also shown. For example, a $V_{\text {overlap }}$ measurement of $\leq 1.8$ indicates the scan was performed within $3 \mathrm{~h}$ of onset (due to specificity of 1 ), and most measurements of $>1.8$ indicate onset $>3 \mathrm{~h}$; however, due to sensitivity of $0.9,10 \%$ of $>1.8$ measurements could be $<3 \mathrm{~h}$.

\section{Discussion}

We compared accuracy and sensitivity of qMRI parameters for discriminating between strokes scanned within and beyond $3 \mathrm{~h}$ of onset. $V_{\text {overlap }}, f_{2}$ and $\mathrm{qT}_{2}$ are far more accurate than $\mathrm{T}_{2}-\mathrm{w}, f_{1}, \mathrm{qT}_{1}$ and ADC. Our data suggest $\mathrm{qMRI}$ is a potential tool for identifying ischaemic stroke patients with unknown onset still within the treatment window, which may aid decision making for pharmacotherapy.

This study agrees with our previous study that quantitative MR relaxation times are more accurate for stroke onset determination than signal intensities in respective relaxationweighted images [5]. High accuracy of relaxation times is likely due to the fact that fitting 
signal intensities to the MR relaxation equations removes inherent variations caused by technical factors such as magnetic field inhomogeneities and proton density [4]. A further benefit of $V_{\text {overlap }}, f_{1}$ and $f_{2}$ is their insensitivity to magnetic field variation within the ischaemic lesion [7]. SNR was higher for summed weighted images suggesting poor SNR cannot account for inferior performance of signal intensities.

Our results suggest quantitative volumes of tissue with elevated relaxation times $\left(V_{\text {overlap }}\right.$ $f_{2}$ ) may perform better in onset time estimation than hemispheric differences of $\mathrm{qT}_{1}$ or $\mathrm{qT}_{2}$. Sensitivity was zero for ADC and low for $\mathrm{T}_{2}$-w. Indeed, in clinical acute stroke cases, ADC was deemed to carry no timing information, but rather serves as an early MRI index of ischaemia per se [5]. Similarly, low sensitivity of $\mathrm{T}_{2}-\mathrm{w}$ was reported clinically [3]. Thus, $\mathrm{ADC}$ or $\mathrm{T}_{2}-\mathrm{w}$ alone can be regarded as poor indices for stroke timing, but instead are important for stroke diagnosis. It should also be recognised that as the rat brain is comprised mainly of grey matter [7] and ischaemic lesions extend differentially within tissue types [9], present findings are representative only of grey matter.

A common concern regarding qMRI for stroke timing in clinical settings includes the long scan times required for $\mathrm{T}_{1}$ and $\mathrm{T}_{2}$ quantification, which increases the possibility of motioninduced artifacts and would delay treatment. However, fast $\mathrm{qT}_{1}$ and $\mathrm{qT}_{2}$ mapping is currently possible in clinical systems, and with the recent advent of MR fingerprinting, which provides many quantitative MR results simultaneously, the future of qMRI for clinical use is promising [10].

To conclude, from the multiple qMRI parameters studied here, $V_{\text {overlap}}, f_{2}$ and $\mathrm{qT}_{2}$ quantified in the low ADC lesion provide the most accurate stroke onset times. The current preclinical data encourage investigation of $V_{\text {overlap }}, f_{2}$ and $\mathrm{qT}_{2}$ as surrogates for stroke timing in clinical settings.

\section{Acknowledgements}

B.L.M. is funded by the EPSRC PhD studentship. Funding by The Dunhill Medical Trust is appreciated. M.J.K. is supported by an Elizabeth Blackwell Institute early career fellowship ISSF2: 105612/Z/14/Z.

\section{References}

1 Kauppinen RA: Multiparametric magnetic resonance imaging of acute experimental brain ischaemia. Prog Nucl Magn Reson Spectrosc 2014;80:12-25.

2 Wu 0, Schwamm LH, Sorensen AG: Imaging stroke patients with unclear onset times. Neuroimaging Clin N Am 2011;21:327-344.

- 3 Cheng B, Brinkmann M, Forkert ND, Treszl A, Ebinger M, Köhrmann M, Thomalla G: Quantitative measurements of relative fluid-attenuated inversion recovery (FLAIR) signal intensities in acute stroke for the prediction of time from symptom onset. J Cereb Blood Flow Metab 2013;33:76-84.

4 Petkova M, Rodrigo S, Lamy C, Oppenheim G, Touzé E, Mas JL, Oppenheim C: MR imaging helps predict time from symptom onset in patients with acute stroke: implications for patients with unknown onset time. Radiology 2010;257:782-792.

-5 Rogers HJ, McGarry BL, Knight MJ, Jokivarsi KT, Gröhn OHJ, Kauppinen RA: Timing the ischaemic stroke by 1H-MRI: improved accuracy using absolute relaxation times over signal intensities. Neuroreport 2014;25: 1180-1185.

6 Madai VI, Galinovic I, Grittner U, Zaro-Weber O, Schneider A, Martin SZ, von Samson-Himmelstjerna FC, Stengl KL, Mutke MA, Moeller-Hartmann W, Ebinger M, Fiebach JB, Sobesky J: DWI intensity values predict FLAIR lesions in acute ischemic stroke. PLoS One 2014;9:e92295.

7 McGarry BL, Rogers HJ, Knight MJ, Jokivarsi KT, Sierra A, Gröhn OHJ, Kauppinen RA: Stroke onset time estimation from multispectral quantitative magnetic resonance imaging in a rat model of focal permanent cerebral ischemia. Int J Stroke 2016;11:677-682. 
-8 Madai VI, Wood CN, Galinovic I, Grittner U, Piper SK, Revenkar GS, Martin SZ, Zaro-Weber O, Moeller-Hartmann W, von Samson-Himmelstjerna FC, Heiss W, Ebinger M, Fiebach JB, Sobesky J: Clinical-radiological parameters improve the prediction of the thrombolysis time window by both MRI signal intensities and DWI-FLAIR mismatch. Cerebrovasc Dis 2016;42:57-65.

-9 Berner L, Cho T, Haesebaert J, Bouvier J, Wiart M, Hjort N, Klaerke Mikkelsen I, Derex L, Thomalla G, Pedraza S, Ostergaard L, Baron J, Nighoghossian N, Berthezene Y: MRI assessment of ischemic lesion evolution within white and gray matter. Cerebrovasc Dis 2016;41:291-297.

10 Ma D, Gulani V, Seiberlich N, Liu Kecheng, Sunshine JL, Duerk JL, Griswold M: Magnetic resonance fingerprinting. Nature 2013;495:187-192. 